\title{
Revisiting the Contribution of Literal Meaning to Legal Meaning
}

\author{
BRIAN FLANAGAN*
}

\begin{abstract}
Many theorists take the view that literal meaning can be one of a number of factors to be weighed in reaching a legal interpretation. Still others regard literal meaning as having the potential to legally justify a particular outcome. Building on the scholarly response to HLA Hart's famous 'vehicles in the park' hypothetical, this article presents a formal argument that literal meaning cannot be decisive of what's legally correct, one which, unusually, makes no appeal to controversial theories within philosophy of language or literary criticism. If the argument is sound, it follows that an enactment's literal meaning neither weighs in the determination of correct legal outcomes nor permits the application of a sequencing model, ie a non-monotonic logic, to its interpretation. These implications are considerably more controversial within contemporary legal theory than the idea that a statute's literal meaning is not necessarily its legal meaning. Yet we see that, given an intuitive notion of legal truth, they follow from it nonetheless.
\end{abstract}

This article takes as its target the idea that literal meaning is legally decisive. It might therefore be charged with seeking to flog a dead horse. Certainly, few legal theorists now believe that a statute's literal meaning is necessarily its legal meaning. ${ }^{1}$ Yet, the idea that an enactment's literal meaning cannot be decisive of a correct legal outcome is too radical for most. Thus, many theorists take the view that literal meaning weighs as one of a number of determining factors, ie are open to believing that 'the weight of plain meaning as a decisional factor increased noticeably in the Supreme Court during its [X] Term'. ${ }^{2}$ Still others regard literal meaning as having the potential to legally justify a particular

* Ad Astra Doctoral Scholar, School of Law, UCD. Email: brian.flanagan@ucd.ie. I would like to thank Maria Baghramian, Gerard Casey, John O'Dowd and Colin Scott for reading earlier versions. I am also grateful to my Philosophy of Law students at UCD and to those attending the Irish Jurisprudence Society's workshop of 13 November 2008 for their comments.

${ }^{1} \mathrm{John}$ Manning is a prominent exception; ' $[\mathrm{R}]$ espect for the legislative process requires judges to adhere to the precise terms of statutory texts' and precludes them 'from making ad hoc exceptions to generally worded laws'. 'The Absurdity Doctrine' 116 Harv L Rev 2387-486 (2003), 2390, 2391.

${ }^{2}$ Fred Schauer, 'The Practice and Problems of Plain Meaning' 45 Vand L Rev 715-42 (1992), 716. The passage, concerning the US Supreme Court's 1989-90 Term, continues, 'This descriptive claim fits with Judge Wald's conclusions...., and appears to be acknowledged as well by Professors Macey and Miller... and elsewhere by Professors Eskridge and Sunstein.' (Citations omitted). See n 39, below.

(C) The Author 2009. Published by Oxford University Press. All rights reserved. For permissions, please e-mail: journals.permissions@oxfordjournals.org 
outcome. $^{3}$ If such assumptions are in fact mistaken, some rethinking is in order. On the other hand, the most prominent refutations of the decisiveness of literal meaning rest on contested views about language and intention. ${ }^{4}$ This article attempts to disrupt the apparent consensus on the place of literal meaning. Drawing on the scholarly response to HLA Hart's famous 'vehicles in the park' hypothetical, ${ }^{5}$ it presents a formal argument that literal meaning cannot be decisive of what's legally correct; one which makes no appeal to controversial theories within philosophy of language or literary criticism. The argument excludes the possibility - as many of Hart's critics do not-that a provision's literal meaning can be one of a number of factors to be weighed in determining its legal meaning or that it can legally justify a particular outcome.

What is a statute's literal meaning? Until recently, most discussions of literal or plain legal meaning concerned the meanings conventionally attributed to a statute's words. This focus paralleled the dominance of descriptivist semantics in analytic philosophy, according to which a word's meaning is entirely a matter of linguistic convention. Since the 1970s, the applicability of this theory to certain kinds of words, most notably proper names and natural kind terms, has been questioned. ${ }^{6}$ Alternative 'externalist' theories of meaning have been proposed, which claim that meaning and reference are not solely determined by the ideas we associate with words. One consequence of this development has been an attempt, by legal theorists, to apply the teachings of semantic externalism to problems in legal philosophy, specifically, to offer an explanation of the phenomenon of disagreement about legal meaning. ${ }^{7}$ According to such theorists, semantic meaning is not the meaning conventionally attributed to the words of statutes, but something more objective. On this approach, legal meaning is indeed a function of semantic or literal meaning, but where the latter is something 'outside the head'. We will focus on meaning that is 'inside the head', that is, on the meanings conventionally attributed to a statute's words. The focus is appropriate for two reasons. First, virtually all participants in debates about the legal decisiveness of literal or semantic meaning have

\footnotetext{
${ }^{3}$ Robert Alexy and Neil MacCormick are among many who defend this view. See $\mathrm{n}$ 31, below.

${ }^{4}$ Legal theorists have relied on the radical contextualism advanced by Searle, Travis and Recanati to refute the legal decisiveness of literal meaning, see F Poggi, 'Semantics, Pragmatics and Interpretation' in P Comanducci and others (eds), Analisi e diritto (Giapichelli, Torino 2008) 159, 162, 168; D Canale and G Tuzet, 'On Legal Inferentialism: Toward a Pragmatics of Semantic Content in Legal Interpretation?' 20 Ratio Juris 32-44 (2007), 35; R Charnock, 'Lexical Inderrminacy: Contextualism and Rule-following in Common Law Adjudication' in A Wagner and others (eds) Interpretation, Law and the Construction of Meaning (Springer, Dordrecht 2006) 21, 36-8; D Sosa, 'The Unintentional Fallacy' 86 Cal L Rev 919-38 (1998), 927, 930; J Goldsworthy, 'Marmor on Meaning, Interpretation, and Legislative Intention' 1 Legal Theory 439-54 (1995).

${ }^{5}$ HLA Hart, 'Positivism and the Separation of Law and Morals' 71 Harv L Rev 593-629 (1958), 606-15.

${ }^{6}$ See eg S Kripke, 'Naming and Necessity' in G Harman and others (eds), Semantics of Natural Language (Reidel, Dordrecht 1972) 253; K Donnellan, 'Proper Names and Identifying Descriptions' 21 Synthese 335-58 (1970); H Putnam, 'The Meaning of "Meaning"' in K Gunderson (ed) Language, Mind and Knowledge. Minnesota Studies in the Philosophy of Science (U Minn Press, MN 1975) 131.

${ }^{7}$ M Moore, 'The Semantics of Judging' 54 S Cal L Rev 151-294 (1981); D Brink, 'Legal Theory, Legal Interpretation, and Judicial Review' 17 Phil \& Pub Affairs 105-48 (1988), N Stavropoulos, Objectivity in Law (OUP, Oxford 1996) and, arguably, R Dworkin, 'Hart's Postscript and the Character of Political Philosophy' (2004) 24 OJLS 1-37, 11-13. But see R Dworkin, fustice in Robes (Harv U Press, MA 2006) 11-12, 227.
} 
taken themselves to be arguing over the decisiveness of the meanings conventionally attributed to a statute's words. Second, while the general implications of the externalist advance are controversial within philosophy of language, ${ }^{8}$ its application to statutory interpretation is even more so. ${ }^{9}$ Accordingly, semantic externalism is not the strongest foundation on which to build a general critique of the legal decisiveness of literal meaning, as it is traditionally understood.

In what follows, we will define an utterance's 'literal meaning' as the proposition you would attribute to it if you referred to just the symbols in question and the appropriate community's conventions on linguistic meaning, ie to the appropriate set of rules for the meanings of words and sentence construction. ${ }^{10}$ Already in this definition, the identification of an utterance's literal meaning seems to involve recourse to non-literal factors. How are we to decide which set of linguistic conventions is appropriate for deciphering an utterance's literal meaning? In justifying our selection of a particular set, are we not obliged to invoke an interest in the author's communicative intent? If so, the literalist interpreter's stated interest in an utterance's literal meaning, rather than in its author's intent, might seem a mere fiction. ${ }^{11}$

This is a potent argument. But it seems to lack general application. In circumstances where a legislature is established in a superior law such as a constitution, it is possible that the law specifies the set of linguistic conventions by which the legislature's utterances are to be understood. While identifying that utterance's literal meaning seems to require recourse to non-literal factors, we need not demand of the literalist that they rely on literal meaning all the way down. We might say that, whereas the intent of constitutional authors fixes the set of linguistic conventions with which a particular statute is to be understood, that of the authors of the statute itself is immaterial. Thus, it seems possible to concede that reliance on authorial intent is necessary to establish the appropriate linguistic conventions, but to deny that one must rely on the intent of the author of the utterance of interest.

\footnotetext{
${ }^{8}$ The school of thought commonly referred to as two-dimensionalism offers an interpretation of Kripke and Putnam's work that retains an essential role for description in semantic meaning. For an overview and synthesis, see D Chalmers, 'The Foundations of Two-Dimensional Semantics' in M Garca-Carpintero and J Macia (eds), Two-Dimensional Semantics (OUP, NY 2006) 55. Even philosophers who favour a broad reading of the implications of the externalist critique may be cautious about the prospect of deriving positive semantic theories from it, see eg M Devitt and K Sterelny, Language and Reality (MIT Press, MA 1999) 79-81, 92.

${ }^{9}$ For example, S Munzer, 'Realistic Limits on Realist Interpretation' 58 S Cal L Rev 459-75 (1985); B Bix, 'Michael Moore's Realist Approach to Law' 140 U Pa L Rev 1293 (1992); A De Moor, 'Nothing Else to Think? On Meaning, Truth and Objectivity in Law' (1998) 18 OJLS 345-62; M Green, 'Dworkin's Fallacy, or What the Philosophy of Language Can't Teach Us about the Law' 89 Va L Rev 1897-952 (2003); J Coleman and O Simchen, 'Law' 9 Legal Theory 1-41 (2003); D Patterson, 'Dworkin on the Semantics of Legal and Political Concepts' (2006) 26 OJLS 545-57; Brian Leiter, 'Naturalism in Legal Philosophy' (2007) < http:// plato.stanford.edu/entries/lawphil-naturalism/> accessed 15 October 2009.

${ }^{10}$ Not all utterances will have propositional content, of course, but those of the legal variety will insofar as they purport to regulate conduct.

${ }_{11}$ Intentionalist legal theorists have raised just this problem; eg WB Michaels and S Knapp, 'Intention, Identity, and the Constitution' in G Leyh (ed), Legal Hermeneutics (U Cal Press, Berkeley 1992) 187, 192.
} 
We will grant the literalist the plausibility of this move and accordingly focus our attention on statutes enacted by legislatures whose authority has been legally provided for. Consideration of the much discussed quality of legal 'defeasibility' will lead us to present a formal argument against the legal decisiveness of literal meaning. We proceed then to defend the argument's premises. Having secured our conclusion, we consider its negative implication for the idea that literal meaning may be one of a number of factors to be weighed in determining an enactment's legal meaning. Finally, we return to Hart's famous park hypothetical to reassess the state of argument. Our project is primarily critical; we offer no argument with respect to what in fact determines an enactment's legal meaning. This focus is not intended to imply that nothing general may be said about what sort of considerations count as determinants of legal meaning. On the contrary, our argument is premised on intuitions about legal meaning that may well be a response to some particular kind of interpretive object. Moreover, we offer no objection to the idea that enactments' literal meaning is of great assistance in determining their legal meaning. Our argument seeks merely to refute the stronger thesis that an enactment's literal meaning may be decisive of its legal meaning.

\section{Defeasibility}

When legal theorists discuss defeasibility, it's usually about whether the application of a legal rule or concept has been defeated. We shall follow a change of tack suggested by the late Neil MacCormick. ${ }^{12}$ Every contending or potential litigant wants to do/realize something to the exclusion of another's desire to do/realize something. We shall call this an 'adjudication interest'; a desire to be able to do/realize something that is asserted to be upheld by the law to the exclusion of another. ${ }^{13}$ Now what a litigant sues over on a particular occasion is unique-I want to realize ownership in a particular house claimed by another, having made an oral contract, with a man named Jim, in front of two witnesses, facing east, on the way to the airport etc. My interest in owning the house bears those innumerable characteristics, only some of which will be legally relevant. The characteristics of the contending interests comprise the facts of the case. We will take it that it is such 'adjudication interests' that are defeasible rather than rules. On this approach, defeasibility becomes a universal phenomenon; it occurs whenever an interest asserted to be upheld by an enactment to the exclusion of another is found to have a characteristic which defeats that prospect. The new tack offers one major advantage. We can easily imagine how an adjudication interest might be defeated in an act of

\footnotetext{
12 'Defeasibility in Law and Logic' in Z Bankowski and others (eds), Informatics and the Foundations of Legal Reasoning (Kluwer, MA 1995) 99.

${ }^{13}$ We may contrast this with the broader notion of interest - as what we desire for ourselves, or as that which would be good for us to have.
} 
legal interpretation. In contrast, imagining how an act of interpretation may defeat a controlling rule is somewhat difficult. If this difficulty is a product of intuitions we hold about the nature of rules, our change will be worthwhile. After all, we debate defeasibility in an effort to establish, by elimination, what's decisive in legal interpretation. If we think it's in the nature of a legal rule to be decisive, taking an enactment's literal meaning as a 'legal rule' will prejudge the question of its decisiveness.

It's a commonplace that legislatures have limited drafting resources. We might expect then that adjudication interests will sometimes possess characteristics that ought to disqualify them from an enactment's protection but which are unspecified in its text, and that interests lacking characteristics specified as necessary in its text sometimes ought to qualify for its protection. Recall the famous Riggs v Palmer ${ }^{14}$ scenario. John wants to realize his inheritance having murdered the testator. The relevant enactment says nothing about disqualification for murder. The will is otherwise valid. Nevertheless, John fails to inherit having triggered an unspecified disqualifying condition of murdering one's benefactor. Jim, the executor, seeks to deny John a share of the testator's estate. But to do so, the enactment specifies that inheritance for John must be contrary to the last recorded expression of the testator's intention. Notwithstanding the fact that inheritance for John is in keeping with the last recorded expression of the testator's intention, Jim succeeds in law. John and Jim's respective adjudication interests are both characterized by the fact that John murdered the testator. In Riggs, this characteristic was found to have legal implications for the success of their interests that were unspecified in the Statute of Wills.

Now consider the road traffic offence of running a light or exceeding a speed limit. Let's say that at the time our car ran the light or broke the limit, the wind was lightly blowing in a north westerly direction. The road traffic statute says nothing about wind direction. What is the judge to do? Does the direction of the wind at the relevant time and place mean that no offence has been committed? Why not? The judge can't seem to rely on the notion that circumstances unmentioned in the text must be irrelevant. Had an earthquake sent the vehicle over the line or the limit, we wouldn't regard it as irrelevant to the question of whether the driver was guilty of the offence. Enactments could of course be written in such a way as to deal with wind direction and earthquakes; what the examples suggest is that a particular case will always contain some circumstance unmentioned by an existing enactment, where that omission alone cannot determine the circumstance's relevance to which interest should prevail. It's a short hop from here to concluding that in choosing between the interests asserted in a dispute about an enactment's legal meaning, its text is never decisive. Reaching this conclusion requires explaining the failure of the traditional understanding of exceptional cases; that an

\footnotetext{
${ }^{14}$ Riggs v Palmer (1889) 115 NY 506.
} 
enactment's literal meaning decides the correct legal outcome except where an absurdity would result. ${ }^{15}$

\section{Literal Meaning as Legal Meaning}

\section{A. The Argument}

(P1) There are scenarios where defeat isn't legally the correct outcome for an interest whose defeat is entailed by the literal meaning of a valid enactment which is the product of finite drafting resources

(P2) Every enactment is the product of finite drafting resources Therefore (P1, P2)

(C1) The literal meaning of an enactment isn't necessarily its legal meaning Therefore,

(C2) Legal meaning is not literal meaning Therefore,

(C3) A fact about something's literal meaning is not a fact about its legal meaning

(P3) The literal meaning of an enactment is its legal meaning only in virtue of a fact about its legal meaning

Therefore (C3, P3),

(C4) For any enactment, the fact that it has a particular literal meaning cannot be decisive of its legal meaning

Therefore,

(C5) For any scenario, an enactment's literal meaning cannot be decisive of the correct legal outcome.

Critiques of the legal decisiveness of literal meaning have tended to focus on the possibility of non-literal utterance meaning generally. ${ }^{16}$ But the generalist

\footnotetext{
15 The traditional understanding remains well defended, see eg WJ Waluchow, 'Defeasibility and Legal Positivism' in J Ferrer and others (eds), Essays on Legal Defeasibility (OUP forthcoming); A Barak, Purposive Interpretation (Princeton University Press, NJ 2006) 80; R Tur, 'Defeasibilism' (2001) 21 OJLS 355-68, 368; K Greenawalt, 'The Nature of Rules and the Meaning of Meaning' 72 Notre Dame L Rev 1449-77 (1998), 1472-3. It can be traced to Aristotle's Nicomachean Ethics 5, 10, 'For when the thing is indefinite the rule also is indefinite, like the leaden rule used in making the Lesbian moulding; the rule adapts itself to the shape of the stone and is not rigid and so too the decree is adapted to the facts.' < http://www.constitution.org/ari/ ethic_00.htm> accessed 15 October 2009.

${ }^{16}$ For example, WB Michaels, 'Against Formalism' in S Levinson and others (eds), Interpreting Law and Literature (Northwestern U Press, IL 1988) 215, 220-5; M van Hoecke, Law as Communication (Hart, Oxford 2002) 132; T Booher, 'Putting Meaning in Its Place: Originalism and Philosophy of Language' 25 Law \& Phil
} 
approach seems to overlook the possibility of a convention whereby the utterances of legislative authors lack ironic, counter-attributive or metaphorical meanings; 'what matters here is simply the intentionality of 'yea' or 'nay' in relation to a given text, not any hopes, aspirations or understanding that may have accompanied the vote'. ${ }^{17}$ In contrast, our argument allows for any special feature that legislative utterances might possess; it appeals specifically to our intuitions about legal meaning. Moreover, P1 concerns scenarios in which literal entailments are legally incorrect, not just ethically or prudentially problematic. As such, it sidesteps the distinction between the questions of what following a rule consists in, and whether it ought to be followed in the circumstances. Thus, if we suppose that enactments are suspended in cases where their literal entailments are ignored, we're left explaining how the contraliteral outcomes may appear legally correct, not just ethically or prudentially so-indeed the outcomes might be neither ethical nor prudential. ${ }^{18}$

As we noted at the outset, most theorists agree with our first conclusionthat the literal meaning of an enactment isn't necessarily its legal meaning. Such theorists may start with $\mathrm{C} 1$ and continue from there. Those who do not already agree with $\mathrm{C} 1$ are perhaps unlikely to accept $\mathrm{P} 1$ - that there are scenarios where defeat isn't legally the correct outcome for an interest whose defeat is entailed by the literal meaning of a valid enactment which is the product of finite drafting resources. Be that as it may, the formulation of P1 challenges those who reject it to find a way of accounting for common intuitions about the legal correctness of certain apparently counter-literal outcomes. We will consider some ways in which literalists have attempted to meet this challenge both in the following section and in revisiting Hart's park hypothetical at the conclusion of the article.

387-416 (2006), 394-400; Poggi (n 4) 168; S Soames, 'Interpreting Legal Texts: What Is, and What Is Not, Special about the Law' in Philosophical Essays (vol 1, Princeton University Press, Princeton, NJ 2008) 403, $408-10$.

${ }^{17} \mathrm{~J}$ Waldron, 'Legislators' Intentions and Unintentional Legislation' in A Marmor (ed) Law and Interpretation (OUP, Oxford 1995) 329, 353; similarly see M Moore, 'A Natural Law Theory of Interpretation' 58 S Cal L Rev 277-398 (1985), 355-6 'the job of a legislature is to pass statutes, not to form intentions; accordingly, the choice of a legislature that ought to be respected is limited to the statute itself, exclusive of the hopes, fears and intentions that gave rise to its passage'.; M Klatt, Making the Law Explicit (Hart, Oxford 2008) (using Robert Brandom's work on meaning to assert the possibility of 'semantically-clear cases'; esp ch 2); and D Lyons, Moral Aspects of Legal Theory: Essays on Law, Fustice, and Political Responsibility (CUP, Cambridge 1993) 147-9 (arguing that literal meaning is as democratically plausible a basis for constitutional interpretation as reference to authors' intent). Searle himself allows that 'sentences have a conventional meaning independent of whatever authorial intentions they may have been uttered with.'; 'Literary Theory and Its Discontents' 25 NLH 637-67 (1994), 656. If so, then absent some argument to the contrary, the literalist can claim that a statute's legal meaning is just its literal meaning alone.

${ }^{18}$ It's worth noting that our conclusion entails very little about how we identify an enactment's legal meaning; it just implies that doing so requires more than a theory of its literal meaning. Thus the argument allows-as surely it must - that the literal meaning of an enactment is an essential resource for its legal interpretation. As Lysander Spooner observed, 'if the intentions could be assumed independently of the words, the words would be of no use, and the laws of course would not be written'. The Unconstitutionality of Slavery (Dela Marsh, Boston 1847) 222. See similarly, W Sinnott-Armstrong, 'Word Meaning in Legal Interpretation' 42 San Diego L Rev 465-92 (2005), 484. 


\section{B. Premise 1-Counter-literal Yet Legally Correct?}

Few would deny that our first premise applies to modern common law jurisdictions. But a critic might appeal to the possibility of other legal cultures, more 'formalist' than our own. ${ }^{19}$ Of course, to undo the premise, the appeal must point to more than mere logical possibility; P1 makes no claim about what is necessarily the case. Yet to show the existence of a current or historic jurisdiction in which literally entailed outcomes are invariably correct, the critic would need unlikely evidence. Specifically, she would need examples of judges for whom it's plausible that every possible scenario where an interest's defeat is literally entailed is one in which its defeat is legally correct. Perhaps there has been such a judge. ${ }^{20}$ I can't imagine one. Admittedly, such scepticism might just be a product of our Anglo-American legal culture. But our ability to point to at least a single outcome that would undoubtedly be deemed legally incorrect, but which is entailed by the literal meaning of a jurisdiction's statute book, seems undeniable. ${ }^{21}$

Most theorists accept our first premise. But consider a move that would block P1 by changing the object of semantic concern from the individual word to the sentence. Andrei Marmor offers an interpretation of Wittgenstein's rulefollowing considerations to hold that literal meaning is indeed legal meaning. ${ }^{22}$ The idea appears to be this; since the use of a sentence determines the criteria of its correct application, if we take an enactment's literal meaning to be determined by its use, we won't have occasions when its literal meaning doesn't generate the correct outcome. So since the enactment, 'no vehicles in the park' isn't used to deny police cars entry, the enactment's literal meaning excludes such vehicles from its prohibitive effect; giving us an answer to the question of whether an approaching police car may legally enter. But denying P1 in this way is problematic. To correlate literally entailed and legally correct outcomes, Professor Marmor takes the unit of literal meaning to be the uttered sentence

\footnotetext{
19 For example, Frederick Schauer, 'that several centuries of Anglo-American legal cultures have been comfortable with empowering judges to search for and to correct statutory absurdity' is 'empirically contingent rather than inevitable'. Schauer (n 2) 732; similarly, Schauer, 'A Critical Guide to Vehicles in the Park' 83 NYU L Rev 1109-34 (2008), 1128, 1134.

${ }^{20}$ Attention is sometimes drawn to the Victorian judge John Jervis, who once held that 'If the precise words used are plain and unambiguous ... we are bound to them in their ordinary sense, even though it do lead, in our view of the case, to an absurdity or manifest injustice': Abley v Dale (1851) $11 \mathrm{CB} 378,391$. Contrast Shepherd v Conquest (1856) 17 CB 427, 441-5 (Jervis J).

${ }^{21}$ Definitive confirmation of this appears impossible, but see $\mathrm{N}$ MacCormick and $\mathrm{R}$ Summers, Interpreting Statutes: A Comparative Study (Dartmouth, MA 1991) 461, 485 (observing that all nine legal systems in the study recognized an absurdity doctrine). Note that every legal system is vulnerable to accidents such as, 'this statute repeals all previous laws' instead of 'all relevant previous laws'.

${ }_{22}$ Interpretation and Legal Theory (Hart, Oxford 2005), 112-18, 115, 'the meaning of [legal] rules, like those of all symbols, must be determined by the actions themselves, that is, by the way the rules are used'. Similarly, MJ Detmold, 'Law as Practical Reason' (1989) 48 CLJ 436-71, 438-40 and S Landers, 'Wittgenstein, Realism, and CLS' 9 Law \& Phil 177-203 (1990) (holding that to think of basic social rules as accounting for social regularities 'would be akin to mistakenly conceiving of the Universal Law of Gravitation as accounting for - in the sense of producing - a basic regular feature of the universe, viz., the mutual attraction of masses', n 46, below).
} 
rather than the individual symbol. ${ }^{23}$ But then, taking literal meaning as legal meaning, we discover the troublesome implication that the first time they come to be interpreted, enactments offer no guidance. Thus if an enactment just means whatever it's used to mean, it won't mean anything before it has been used. There would be no obviously correct answer under the park or any other enactment for the first decision on the entrance of police cars, or, for that matter, for the first decision on the entrance of anything. But that scenario is counter-intuitive in relation to most, if not all, enactments. ${ }^{24}$

A legal rule isn't like one of our laws of gravity; its establishment predates our ability to test its predictiveness of outcomes. Curiously, given Marmor's description of easy cases as ones interpreted without regard to an enactment's purpose, his argument compares to that offered by Steven Winter to prove the contrary: that perspicuous cases under the park enactment appear that way because their solutions seem to obviously correspond with (or disrupt) what, culturally, a 'park' is used for. ${ }^{25}$ Unfortunately, Professor Winter's argument carries an equally problematic implication-that counter-cultural legal rules can't produce easy cases of violation. The implication is false. We'll find plenty of such cases by looking at the early days of the British and Irish pub smoking bans, not to mention colonial regimes imposed on majority cultures. If we perceived the meaning of such rules, it's not because we perceived elements of our culture. It might be because we perceived someone else's culture of course, but then the obviousness of the outcome requires more than cultural knowledge; it requires knowing which of contrary cultural positions is legally salient.

\section{Premise 2-Drafting Limits}

There is no mistaking the tension between our second premise and Ronald Dworkin's influential analysis of the logical structure of rules; that there is 'no reason in theory why they [a rule's exceptions] should not all be added on [to its statement], and the more there are, the more accurate is the statement of

\footnotetext{
${ }^{23}$ Contrast with Wittgenstein's focus on the use of individual words; GEM Anscombe (tr), Philosophical Investigations (Macmillan, NY 1953) ss 3, 66-9 (concerning the range of what counts as a 'game').

${ }^{24}$ Marmor might object that the relevant patterns of usage are not just the applications of the enactment in question but the role that the making of that sort of utterance plays in social life. (This possibility was suggested by an anonymous referee.) In principle, this might be a persuasive response. In practice though, the only role played by the utterance of such sentences in social life is the purported application of some enactment or other. Thus, absent an enactment that, 'no vehicles are permitted in the park', who is going to be using that sentence? Practices of using a sentence to describe some distribution of rights or obligations seem unlikely to emerge in the absence of an act to which the sentence might refer. People will of course be using the words the sentence comprises, but reference to the meanings of individual words is what Marmor's strategy seeks to avoid. People will, after all, be using 'vehicle' to refer to police cars and the like.

${ }^{25} \mathrm{~S}$ Winter, A Clearing in the Forest (U Chicago Press, IL 2001) 204-6. See also, NE Simmonds, 'Between Positivism and Idealism' (1991) 50 CLJ 308-29 (citing F Hayek, Law, Legislation and Liberty (Routledge \& Kegan Paul Ltd, London 1973) 134-5); BB Levenbook, 'How a Statute Applies' 12 Legal Theory 71 (2006) (both characterizing enactments as formal instantiations of convergent practices). Similarly, Cass Sunstein has written of legal perspicuity as owing to the presence of 'background norms ... so widely shared, they appear invisible and are not the object of controversy'. 'Norms in Surprising Places' 100 Ethics 803-20 (1990), 807.
} 
the rule'. ${ }^{26}$ There certainly seems no reason why any one 'exception' might not be specified in the statement of a rule. And if we took 'in theory' to mean in a world in which we had unlimited time and patience for drafting, we might perhaps regard rule statements as applying 'all-or-nothing' to a situation, as Dworkin suggested. ${ }^{27}$ In such a world, one might argue that the proposition expressed by the literal meaning of an enactment is necessarily that expressed by its legal meaning. ${ }^{28}$ But there's good reason to think that, in the real world, a legal directive's 'exceptions' couldn't all be formulated, and that hence, it couldn't be followed automatically on recognition of stated facts. The reason is a feature we've already noted; an adjudication interest has a countless number of recognizable characteristics. To conclude that it has the benefit of a legal directive is to hold that none of its characteristics defeat its prospects. We may take an interest's defeat to be 'abstractly pre-determined'; as deriving from a content that's identified, somehow, by the interpreter. ${ }^{29}$ What we can't do is look to a legal directive's limited specification of what is relevant as the criterion of that identification. ${ }^{30}$

Given (P1); that there are scenarios where defeat isn't legally the correct outcome for an interest whose defeat is entailed by the literal meaning of a valid enactment that is the product of finite drafting resources and (P2); that every enactment is the product of finite drafting resources, it follows that the literal meaning of an enactment isn't necessarily its legal meaning (C1). If the literal meaning of an enactment isn't necessarily its legal meaning, it follows that legal meaning is not literal meaning (C2). Equally, if legal meaning is not literal meaning, it follows that a fact about something's literal meaning is not a fact about its legal meaning (C3).

\section{Premise 3- Fustified Legal Decisions as Correct Legal Beliefs}

Our third premise is that the literal meaning of an enactment is its legal meaning only in virtue of a fact about its legal meaning. If, on the contrary, an enactment's literal meaning may be its legal meaning merely in virtue of a fact concerning what has been revealed about some interest or other, our argument

${ }^{26}$ Ronald Dworkin, Taking Rights Seriously (Harv U Press, MA 1977) 25.

27 Ibid 24

${ }^{28}$ Dworkin would add that, to determine the meaning of the law on a particular occasion, one must take into consideration the content of the legal system as a whole, not simply a given enactment. There thus results in no disagreement with Dworkin on the conclusion that literal meaning is not legally decisive, but rather with someone who adopts Dworkin's analysis of rules minus his theory of holistic interpretation.

${ }^{29}$ In contrast to Giovanni Sartor's critique of Dworkin; 'Defeasibility in Legal Reasoning' in Bankowski (n 12) $119,142-4$.

${ }^{30}$ Some have argued that interpreters ought to be constrained to follow literal meaning if that is more likely, on the whole, to lead to a greater number of correct legal outcomes. See Fred Schauer's work on instrumentalist formalism, according to which, given error prone interpreters, treating literal meaning as decisive may result in a greater number of accurate legal judgments overall; Schauer, Playing By the Rules (OUP, Oxford 1991) 137-53. Similarly, Adrian Vermeule has suggested that, given their interpretive limitations, judges should follow literal meaning; Fudging Under Uncertainty (Harv U Press, MA 2006) 183-230. Consideration of instrumental formalism is outside the scope of this article. 
for C5-that an enactment's literal meaning cannot be decisive of the correct legal outcome-fails. But some theorists deny P3. Their objection is that, 'until (or unless) some factual evidence on the defeating conditions is forthcoming (one way or the other), the concept or rule simply does apply to the facts already at hand'. ${ }^{31}$ If the conditions stated in an enactment are satisfied, and no evidence of a fact triggering some defeating condition is forthcoming, then the outcome entailed by stated conditions is the correct legal outcome. If so, an enactment's literal meaning may become its legal meaning in virtue of what has been revealed about an interest's characteristics. Since a fact concerning what has been revealed about an interest's characteristics is not a fact about the meaning of an enactment, P3 is false. We shall label this objection the 'sequencing' model of statutory interpretation - the idea that literal meaning is legally decisive unless or until something is forthcoming about a 'defeating condition'. ${ }^{32}$

In assessing the sequencing model, we come quickly to the distinction between truth and justified belief. ${ }^{33}$ The determinations we make as to what's true carry the caveat that we've had access to all relevant information in making them. Even where we've made justified determinations about past events, we're happy to correct ourselves to better reflect truth, should further information arise. This readiness to revise our justified beliefs distinguishes our concept of truth from our concept of justified belief. ${ }^{34}$ Similarly, a determination as to what's legally correct carries the caveat that we've had access to all relevant information. Should new information arise that suggests it was wrong, albeit justified, we revise it-even when taking the losing party to lack further legal recourse. It seems that, in keeping with our determinations about truth generally, our conclusions about the correctness of legal outcomes assume an optimal body of evidence about the interests in litigation-not a sub-optimal one, however justifiable its shortage of relevant information. Sequencers deny this; they say that the fact that our original determination was justified may make it true. Thus, where on the revealed information one is justified in

${ }^{31}$ B Chapman, 'Law Games: Defeasible Rules and Revisable Rationality' 17 Law \& Phil 443-80 (1998), 451. See Bankowski (n 12), 13 (holding that the implications of a rule - not merely a judge's beliefs about them-are determined by what he knows.); Stavropoulos (n 7) 62 (that there can be no unrevisable legal formula is not to say 'that there can be no defensible, theoretical formula that explains and justifies novel cases' resemblances with the paradigms').

32 'Sequencing' is thus the application to statutory interpretation of non-monotonic logic, ie a logic in which the set of conclusions warranted on the basis of a given knowledge base does not increase with the size of the knowledge base itself. Under classical logic, in contrast, one's inferences, being deductively valid, can never be 'undone' by new information. See further, GA Antonelli, 'Non-montonic Logic' (2006) Stanford Encyclopedia of Philosophy <http://plato.stanford.edu/entries/logic-nonmonotonic/> accessed 15 October 2009.

33 Quietist philosophical theories disputing this distinction run into a minefield of contrary intuitions and practices; see generally J Cohen, 'Truth and Public Reason' 37 Phil \& Pub Affairs 2-42 (2009). Cohen aptly compares the minimalist about truth to someone who knows 'the rules of a game without knowing that the point of games is to win', 25. The comparison seems readily extendible to someone dealing in justified beliefs without recourse to a (distinct) concept of truth.

${ }^{34}$ What Bernard Williams describes as our subjection of our beliefs to 'the disciplines of the virtues of truth'; Truth and Truthfulness (Princeton U Press, NJ 2002) 83. 
believing the outcome entailed by literal meaning is legally correct, that outcome becomes legally correct. But this is doubtful: whereas a litigant's silence may justifiably affect which outcome we think is legally correct, it doesn't seem to affect which outcome is legally correct. The reason is clear enough; we haven't decided in favour of an interest by reference to a normative theory-a theory as to what ought to be done, foregone or permitted-without having taken it to be free of characteristics at odds with that theory. ${ }^{35}$ The idea that defeat was legally correct for an interest which, all evidence revealed, would have been legally successful, is counter-intuitive.

None of this is to say that a party satisfying the literally specified conditions of a rule must first 'imagine and then... disprove all possible legally defeating conditions' ${ }^{36}$ The absence of evidence concerning many of a contending interest's characteristics is inevitable. In these circumstances, an interpreter assumes that its unrevealed characteristics fail to defeat its prospects. Of course if a legal conclusion assumes that something is the case, it won't 'apply to the facts already at hand' save for that being the case. Now we know that where the law provides a uniquely correct outcome, the revision of a legal conclusion isn't due merely to an increased knowledge of a case's facts. Such information might be innocuous - we might learn that the wind was blowing in a north westerly direction at the relevant time and place. On the contrary, the rejection of an apparently correct conclusion as to the legally accommodated interest is due to the failure of one of its original premises-that the non-uncovered facts are legally irrelevant. ${ }^{37}$ The premise's failure results in the invalidity of the inference, leading to a revision. So the fact that we take a literally entailed legal conclusion as justified is due to the assumption that it coincides with the result of a full investigation into the theoretical relevance of the case's features. Our implicit appeal to theory beyond that provided by the enactment's literal meaning reflects P3; that the literal meaning of an enactment is its legal meaning only in virtue of a fact about its legal meaning.

Indeed, in its acceptance of $\mathrm{C} 1$ - that the literal meaning of an enactment isn't necessarily its legal meaning - the sequencing model cannot account for the legal relevance of all the revealed facts about an interest's characteristics. It thereby fails to offer a method of reaching even justified legal decisions. Thus, the sequencing model concedes that an enactment's literal meaning won't specify all the conditions for determining the interests it

\footnotetext{
35 Our discussion of legal truth may be contrasted with Brian Bix's recent article in this journal, 'Global Error and Legal Truth' (2009) 29 OJLS 535-47. Professor Bix is concerned with the truth of beliefs about the law and the possibility that they may be in error. We are concerned with the possibility of justified beliefs about correct legal outcomes being in error; we may assume that interpreters had an accurate understanding of the legal proposition itself.

${ }^{36}$ MacCormick (n 12) 104.

37 As any conclusion will depend equally on the relevance of the uncovered facts, the presence of this assumption doesn't presuppose the truth of any legal outcome. Pace J Hage, Studies in Legal Logic (Springer, Dordrecht 2005) 26-8 (rejecting a classical logic for legal conclusions on the basis that a deduction enabling premise would beg the question of the correct conclusion).
} 
accommodates-hence, its proposed shift from conclusions entailed by the law given the facts, to those entailed by the law given the uncovered facts. Unfortunately, the concession cannot support the proposed shift; the fact that an interest's uncovered characteristics exclusively satisfy the listed conditions won't permit a conclusion to be drawn wherever non-literally specified facts have also been uncovered. Such facts will be uncovered in any third party fact finding process - facts about places, people, times, relationships. But their relevance not having been literally specified, we don't know without further enquiry their impact, if any, on the correct legal outcome. In other words, since we can't tell whether the recognized facts include any at odds with a legal condition 'not to be refuted' by reference to a limited specification of those conditions, we can't decide the outcome by way of such a specification.

We must reject then the common understanding that, '[a] legal judgment J, which follows logically from formulations of legal norms $N_{1}, N_{2} \ldots N_{n}$ whose validity has to be presupposed together with empirical statements $A_{1}, A_{2} \ldots A_{n}$, can be described as justifiable in terms of $\mathrm{N}_{1}, \mathrm{~N}_{2} \ldots \mathrm{N}_{\mathrm{n}}$ together with $\mathrm{A}_{1}$, $\mathrm{A}_{2} \ldots \mathrm{A}_{\mathrm{n}}{ }^{38}{ }^{38}$ In light of what we know about the inadequacy of our powers of rule formulation, we have to accept the inclusion of empirical statements whose legal relevance hasn't been formulated. Given the inclusion of such statements, legal judgments can't be logically derived from formulations of legal norms, no matter how precise. Whatever number of formulated legal clauses the empirical statements satisfy, if we're to reach a conclusion as to what to decide by virtue of $\mathrm{N}_{1 \ldots}$ plus the empirical statements, we must add the assumption that the statements also satisfy the unformulated clauses.

Given that the literal meaning of an enactment is its legal meaning only in virtue of a fact about its legal meaning (P3) and that a fact about something's literal meaning is not a fact about its legal meaning (C3), it follows that, for any enactment, the fact that it has a particular literal meaning cannot be decisive of its legal meaning (C4). If an enactment's literal meaning cannot be decisive of its legal meaning, it follows that, for any scenario, an enactment's literal meaning cannot be decisive of the correct legal outcome (C5).

\section{Possible Literal Decisiveness?}

While the sequencing model holds that a provision's literal meaning may solely decide a legal question, the traditional response to counter-literalist hypotheticals has been to count literal meaning as just one factor to be weighed. ${ }^{39}$

\footnotetext{
${ }^{38}$ R Adler, N MacCormick (trs) and R Alexy, A Theory of Legal Argumentation (OUP, NY 1989), 2. On even pragmatist accounts of legal reasoning we find this understanding implicit; eg E Patterson, 'Logic in the Law' 90 U Pa L Rev 875-909 (1942), 908.

39 Thus in response to Fuller, Hart notes that 'For a legal system often has other resources besides the words used in the formulations of its rules which serve to determine their content or meaning in particular cases. Thus... the obvious or agreed purpose of a rule may ... serve to show that words in the context of a legal rule may have a meaning different from that which they have in other contexts.' Hart, Essays in furisprudence and Philosophy
} 
Our problem with the sequencer was that she invoked a counter-intuitively contingent notion of truth. The problem with placing weight on a 'semantic argument', on the other hand, is that for each case it begs a question that must be answered before the law can be ascertained, what decides the legally correct weight? There may be judges for whom the indications of one criterion are sometimes overridden by those of another (literal?) criterion. But neither criterion could be decisive of what's legally correct; their possession of their respective weights presupposes the application of a master legal criterion attributing those weights. The question-begging in attributing a weight to an enactment's literal meaning corresponds with C3 and P3. Take their joint implication; that, for any scenario, an enactment's literal meaning cannot be decisive of the correct legal outcome (C5). If so, then an enactment's literal meaning cannot be a factor that is weighed in determining its legal meaning. Thus, if literal meaning had weight in the determination of an enactment's legal meaning, it must at least be possible for it to be decisive of the correctness of a legal outcome. But this possibility is excluded by $\mathrm{C} 5$.

We know that sometimes the legally correct result contradicts literal meaning; we don't consider officials legally bound to hold Panama Canal Zone born John McCain ineligible for President of the United States. ${ }^{40}$ Quite the opposite. ${ }^{41}$ But the traditionalist maintains that whatever it is that gives us an eligible McCain is sometimes displaced by literal meaning. Take an enacted deadline. Filing something a day or hour afterward will presumably make no difference to whether the recipient has the information in time to make a considered decision on the matter in question. So if the rejection of a barely late filing follows from a correct interpretation of the enactment, is that not an interpretation that works off its literal meaning? And if so, can't literal

(OUP, Oxford 1983) 8. Stephen Munzer and James Nickel foreshadowed this development in Hart's thinking; 'Does the Constitution Mean What It Always Meant?' 77 Colum L Rev 1029-62 (1977), 1055, 1059 (holding that a constitutional bar exists in part because of its being found in the text, where that characteristic is also consistent with a constitutional permission). For recent articulations of the idea of literal meaning as a decisional factor, see T Spaak, 'Legal Positivism, Anti-Realism, and the Interpretation of Statutes' in K Segerberg and R Sliwinski (eds), Logic, Law, Morality (Uppsala U Press, Uppsala 2003) 127, 141; S Rickless, 'A Synthetic Approach to Legal Interpretation' 42 San Diego L Rev 519-32 (2005), and Klatt (n 17) (semantic arguments may be decisive even though 'it is not possible to conclude legal clarity from semantic clarity' 219). Many more contemporary scholars might be cited. For further examples, see n 15, above.

${ }^{40}$ Art 2 of the Constitution (the supreme enactment) states; 'No Person except a natural born Citizen.... shall be eligible to the Office of President'. A property that's 'natural' isn't man made, eg made by legislation. Hence we can't make someone natural born by legislative means - we may only legislate consequences for being natural born. It seems that the mere property of being born could only help qualify one for a privileged legal relationship with a state where birth occurs. Since Senator McCain wasn't born in the United States, the provision's literal meaning entails his ineligibility for the office.

${ }^{41}$ There has been an article disputing this conclusion (though it does note an interpretive path to eligibility). See G Chin, 'Why Senator John McCain Cannot Be President' 107 Mich L Rev First Impressions 1-21 (2008). To my knowledge, no other legal scholar has written in support of Professor Chin's position nor does Chin base his reading of McCain's eligibility on the Constitution's literal meaning. Note the 2008 Senate Resolution unanimously affirming his eligibility; 110th Cong S Res 511. 
meaning be legally decisive after all ${ }^{42}$ Well no. For instance, there are screening, administrative and equality interests in having a deadline that applies regardless of the particular day or hour that happens to be chosen and which dissipate if it may not be adhered to rigidly. Thus, with rigidity, administrators don't have to spend time thinking about (and arguing over) what is a reasonable grace period, eligible documents come from a more organized pool of filers, and the same organizational effort is formally demanded of all applicants. Accordingly, the legal plausibility of deadline-rigid interpretations doesn't show that literal meaning may sometimes trump other candidate criteria, whereas the decision that an enactment's literal meaning be treated as decisive cannot follow from its literal meaning. ${ }^{43}$

\section{Vehicles and the Park}

Shelving our legal theories, we would regard a park attendant who denied an ambulance emergency access to a local park on the basis of a 'no vehicles in the park' enactment as not just a bad person, but as an official whose understanding of the enactment was seriously flawed. ${ }^{44}$ There is no English linguistic convention by which the meaning of the sentence, 'Vehicles are not permitted in the park' excludes ambulances (or police cars). The literalist may attribute to context or background our understanding that the enactment permits the entry of such vehicles. ${ }^{45}$ To attribute our understanding to context, however, we need to have ideas about what is contextually relevant, whereas having such ideas presupposes a non-literal criterion of legal meaning-what Abner Greene has characterized as the 'missing step of textualism'. ${ }^{46}$ The literalist might then seek to characterize such ideas as in fact deriving from linguistic convention by invoking historical patterns in the enactment's usage. Yet as we discovered with respect to Marmor's semantic strategy, this move can't account for the potential obviousness of an enactment's counter-literal legal meaning on the occasion of its first application to some question.

\footnotetext{
${ }^{42}$ Professor Schauer uses the example of United States $v$ Locke (1985) 471 US 84 to this effect; Schauer (n 2) 728-42; Schauer, 'Is Defeasibility and Essential Property of Law?' in J Ferrer and others (eds), Essays on Legal Defeasibility (OUP forthcoming).

${ }^{43}$ Compare, S Burton, Fudging in Good Faith (CUP, NY 1992), 178 (countenancing literal decisiveness 'when the purpose of the law is only to coordinate an activity fairly, or when the law seeks to encourage reliance and someone has reasonably relied on its determinacy.').

${ }^{44}$ We think this, even though we may sometimes place value on an explicit handling of such points, eg Buckoke v GLC [1971] 1 Ch 655. A remark of the Victorian jurist James Fitzjames Stephen suggests an explanation; 'people continually try to misunderstand...therefore it is not enough to attain to a degree of precision which a person reading in good faith can understand; but it is necessary to attain if possible to a degree of precision which a person reading in bad faith cannot misunderstand', Re Castioni [1891] 1 QB 149, 167.

45 Note that for deictic words, eg 'now', literal meaning prescribes the relevance of a particular element of the context of any utterance thereof (in this case the time of utterance).

46 'The Missing Step of Textualism' 74 Fordham L Rev 1913-36 (2006). Consider Manning (n 1) 2463, 'If "drew blood" does not apply to an emergency medical procedure, it is because of a settled social connotation that associates that phrase, in predictable contexts, with acts of aggression.'
} 
Notice how the hypothetical concerns adjudication by a low-level functionary-allowing it to reflect the general failure of literal meaning to decide legal outcomes. ${ }^{47}$ The failure endures as we move back up the levels. Thus, 'prosecutorial discretion' can't do the work of avoiding the incorrect outcome; neither can 'agency expertise', executive mercy, remedial private bill legislation, nor jury nullification. Such complications fail to rescue literalism because all they do is push the necessary act of interpretation to some further institution. The same problem arises at the next iteration; we simply hold the prosecution authority (etc.) responsible for reaching what we regard as the legally correct yet counter-literal conclusion. So too with the idea that, it being unconstitutionally irrational for ambulances to be prohibited from parks, the intuitively correct result may be achieved in accordance with the literal meaning of (superior) enactments. ${ }^{48}$ At best, this again just pushes the issue back a notch - what if, as for candidate McCain, there is no superior enactment to the one in question? ${ }^{49}$

Finally, we might appeal to the enactment of general 'saving' provisions elsewhere in the legal system. But then if a legislative filter is generally available to avert problematic literal entailments, the system has no literally entailed outcome. Whereas, when we stipulate the absence of further provisions relevant to the ambulance's entry, we retain our intuition as to the correct outcome. We seem obliged to conclude that there's a sense in which Hart was mistaken in suggesting that we could, if we desired, 'freeze the meaning of the rule so that its general terms must have the same meaning in every case where its application is in question'. ${ }^{50}$ We can no more freeze legal meaning to an enactment's semantics than we can recognize as legally correct the prevention of an ambulance from entering the park as a man died needlessly within.

\section{Conclusion}

The argument we've presented purports to show that literal meaning isn't decisive of legally correct outcomes. The argument is specific to legal utterances-it does not depend on a general theory of language or literature. Its truth is contingent in that our intuitions may not support the application of P1 to every legal culture. But we've seen what salient counter evidence to P1

\footnotetext{
47 The hypothetical, now a commonplace, is owed, of course, to Lon Fuller's original truck-as-memorial example; 'Positivism and Fidelity to Law - A Reply to Professor Hart' 71 Harv L Rev 630-72 (1958), 663.

${ }^{48}$ See Manning, 'Textualism and the Equity of the Statute' 101 Colum L Rev 1-127 (2001), 115, 118-19.

49 John Nagle advocates barring legal interpretations sensitive to 'scrivener's error' and 'absurd results' in light of the rarity of the cases in which such allowances are needed to avert an incorrect result. 'Textualism's Exceptions' in D Farber (ed) Dynamic Statutory Interpretation (2002) <http://www.bepress.com/ils/iss3/art15> accessed 15 October 2009. Similarly, Marmor has recognized cases where an act's prescriptive content differs from its semantic content as possible but 'very rare'; 'The Pragmatics of Legal Language' 21 Ratio Juris 423-53 (2008), 429. To the theorist, the point is not that such cases must frequently be confronted, but that our reaction to them follows from the nature of our legal reasoning.

${ }^{50}$ Hart, The Concept of Law (2nd edn OUP, Oxford 1994) 129.
} 
must be, and we can guess how likely we are to find it in any legal culture. If my scepticism on this is merited, and if P2 and P3 correspond with what we observe and intuit about legal interpretation generally, the argument is apparently sound. If so, it follows that literal meaning neither weighs in the determination of correct legal outcomes nor permits the application of a sequencing model, ie a non-monotonic logic, to statutory interpretation. These implications are considerably more controversial within contemporary legal theory than the idea that a statute's literal meaning isn't necessarily its legal meaning. Yet we've seen that, given an intuitive notion of legal truth (P3), they follow from it nonetheless.

One further consequence of the argument is that a common approach to formulating an ideal type of legal 'ruleness' is misleading: 'A legal directive is "rule"-like when it binds a decisionmaker to respond in a determinate way to the presence of delimited triggering facts. ${ }^{.51}$ To characterize automatically triggered directives as at one end of a continuum of the form which legal directives might take is to introduce a straw man; intuitively, we simply don't take the presence of delimited facts as triggering a legal outcome. If the legal sceptics are wrong and our routine legal interpretations reflect what is legally the case-not just what is culturally the case, what is in our class interest or what we had for breakfast - it's not because they reflect, or have given weight, to a literally specified proposition. Theorists who view judges as identifying distinctively legal propositions must look elsewhere.

\footnotetext{
${ }^{51}$ P Schlag, 'Rules and Standards' 33 UCLA L Rev 379-430 (1985), 381. The distinction has played a role in framing arguments about the nature of legal reasoning since Roscoe Pound's Philosophy of Law (Yale U Press, New Haven 1922), 141-2 '[R]ules, where we proceed mechanically, are more adapted to property and business transactions,... [w] [were the call is for individuality in the product of the legal mill, we resort to standards.'. See eg D Kennedy, 'Form and Substance in Private Law Adjudication' 89 Harv L Rev 1685-778 (1976); K Sullivan, 'The Justices of Rules and Standards' 106 Harv L Rev 22-123 (1992); D Nance, 'Rules, Standards, and the Internal Point of View' 75 Fordham L Rev 1287-316 (2006), 1295 (taking 'as primitive the idea that "rules," as normative directives about conduct, are framed in terms of concepts that can be applied ... by specifying operative facts that trigger the rule.').
} 